\title{
Intervention Program to Keep Girls in the Science Pipeline: Outcome Differences by Ethnic Status
}

\author{
Toby Epstein Jayaratne, ${ }^{1}$ Nancy G. Thomas, ${ }^{2}$ Marcella Trautmann ${ }^{3}$ \\ ${ }^{1}$ Institute for Research on Women and Gender, 1136 Lane Hall, 204 South State Street, \\ University of Michigan, Ann Arbor, Michigan 48109-1290 \\ ${ }^{2}$ Science/Art, Aspen, Colorado \\ ${ }^{3}$ Department of Chemistry, Wayne State University, Detroit, Michigan
}

Received 5 November 2001; Accepted 12 September 2002

\begin{abstract}
This study evaluated a 2-week residential program aimed at enhancing the science interest and persistence of high-achieving 8th-grade girls. Questionnaires were administered to 38 program participants (14 of whom were of minority ethnicity) and 173 applicants who did not attend the program, at 3 time points: preprogram, 1 year postprogram, and 4 years postprogram. Outcomes, measured postprogram, included science self-concept and interest, persistence and aspirations in science, science activities, science course-taking in high school, and plans for a science college major. There was no main effect of program participation on any of the outcome measures, but a significant Participation $\times$ Ethnicity interaction effect occurred for all but one of the outcome variables. At Time 2, and especially Time 3, nonminority participants tended to have the most positive outcomes, whereas minority participants tended to have the most negative outcomes, compared with applicants. Post hoc analyses showed that although nonminority girls overall were more advantaged, this difference did not explain results. Several interpretations for these findings are discussed, the most likely that some global feature of the program, not any intervention component, interacted over time with the girls' postprogram experience. (๑) 2003 Wiley Periodicals, Inc. J Res Sci Teach 40: 393-414, 2003
\end{abstract}

As global competition in science and technology intensifies, the U.S. science community must work to optimize our own human capital development. This task falls largely to those science educators who generate curricula and set the goals for teacher training and what students should know. However, there is more. Educators must also address questions of equity-in this case women's and minorities' pursuit of science learning. This is the focus of the present evaluation

\footnotetext{
Contract grant sponsor: Office of Vice President for Research at the University of Michigan.

Correspondence to: T.E. Jayaratne; E-mail: tjayarat@umich.edu

DOI 10.1002/tea.10082

Published online in Wiley InterScience (www.interscience.wiley.com).
} 
which follows an intervention aimed at affecting persistence in science course-taking by girls generally, and minority girls in particular.

Women have long been underrepresented in the science professions, but in the 1970s and 1980s they made considerable strides toward greater participation. This advancement has stalled, however; women continue to be underrepresented-as science majors, as earners of science degrees, and as science professionals. In 1996, just $19.7 \%$ of first-year college women intended to major in a science, mathematics, or engineering field (S\&E), compared with $31 \%$ of first-year men (National Science Board, 1998). In 1995, women comprised $34.7 \%$ of the bachelor's degrees in S\&E-a disproportion the more striking in that women currently outnumber men in undergraduate college attendance by almost $25 \%$ (National Science Board, 1998). In 1995, women earned $26 \%$ of the master's and $24 \%$ of the doctoral degrees in science. Finally, just 1 in 5 working scientists is a woman, and women tend to be underemployed or concentrated in the lower and middle levels of science occupations, e.g., in teaching or nonprofits (National Science Board, 1998).

Minority group participation in the sciences follows a different course; underrepresentation does not occur until the later stages of training, but ethnicity is found to be more important than gender in determining ultimate professional development in the sciences (Chu Clewell \& Ginorio, 1996). Underrepresented minorities (who for purposes of this report include African Americans, Latinos, and Native Americans, but not Asian Americans, whose science participation on average resembles or exceeds that of majority students) have made substantial gains in higher education in the past 3 decades. College enrollments began to increase markedly in the 1970s (Hossler \& Stage, 1992). At present, underrepresented minorities make up $21 \%$ of the total undergraduate enrollment, which approaches their proportion of the population at large $(21.9 \%)$. Incoming freshman minority students also express the intention to major in science at rates $(23 \%)$ comparable to that of nonminority students (National Science Board, 1998). It is here, however, that the parity begins to erode; the dropout rate of minority students is higher, and they tend to switch out of science into other fields at rates greater than nonminority students (Chronicle of Higher Education, 1997; Farmer, Wardrop, Anderson, \& Risinger, 1995). Like women, minority groups are underrepresented as earners of science degrees and as science professionals. In 1995, minority students constituted just $13.5 \%$ of the bachelor's, $11.4 \%$ of the master's, and $7.4 \%$ of the doctoral degrees in science (National Science Board, 1998).

\section{Interventions and Evaluation}

Persistent underrepresentation of women and minorities in the sciences thus remains a concern, from the standpoint of both equity and human capital development. This situation has spawned a plethora of interventions aimed at increasing the number of women and minorities in science, mathematics, and engineering. Programs have sprung up in a variety of settings-in community centers, businesses, and universities. They vary in their goals: some aim to enhance science literacy and skills, others to affect motivation and enjoyment, still others to combat the stereotypes of who is suited for a science career.

Programs also vary in the age group targeted. Much has been made of the pipeline metaphor that characterizes the attrition of students, particularly girls and minorities, away from science pursuits at crucial points in their development (American Association of University Women, 1991; Eccles, 1997; Kahle, 1996; Widnall, 1988). Some interventions have focused on those transition points in schooling thought particularly important - the point when students enter junior high school, when they pass from junior into high school, or when they graduate from high school. In middle school or the beginning of junior high school, for example, girls' self-concept of their 
abilities, more than that of boys, begins to decline (Anderman \& Maehr, 1994; Eccles, 1997; U.S. Department of Education, 1998), an earlier strong interest in science notwithstanding. This is held to be a vulnerable time because this is also the point when students first encounter choices in curriculum, including whether to take more or less science or mathematics.

Despite the many programs, however, it is unclear how successful they have been in increasing the number of girls overall and minority girls in particular taking science and aspiring to science careers. First, few programs have been evaluated. Even when evaluations are included, results are often inconclusive (Davis \& Rosser, 1996). Of those programs that have been evaluated, few show program effects. Fewer still have investigated or demonstrated effects on minority girls' or young women's participation in the sciences (e.g., Astin \& Astin, 1992; Matyas \& Malcom, 1991). Interventions tend to be short-term, with assessments taken immediately postprogram without follow-up. Many programs focus on mathematics, rather than on science per se. Many target a narrow range of outcomes (e.g., the liking of science) and do not assess whether attitude change, if it does occur, leads to course-taking that keeps students (particularly girls and minorities) in the pipeline. Many early reports are anecdotal; only gradually has the research become more informative.

A review, for example, of 300 precollege programs reported no outcomes; in a follow-up survey of 336 programs, the findings provided few insights; less than half had included an evaluation component (reported in Matyas \& Malcom, 1991). Outcome measures such as whether a program grows in participant numbers or is successful in attracting continuing funding (Clewell, Anderson, \& Thorpe, 1992) do not contribute much to our understanding of what elements of intervention help maintain a student's interest in science or her ongoing pursuit of science training.

Two interventions illustrate a more targeted approach. The first (Mason \& Kahle, 1988) sought to promote a "stimulating gender-free learning environment" for ninth graders. Twelve teacher volunteers of 24 general biology classes (student $N=550$ ) were randomly assigned to experimental and control conditions. The six experimental teachers took a summer Science Spark workshop that presented methods and materials held to encourage girls in science. Students were assessed in the following year on measures of attitudes toward science, perceptions of science, extracurricular science activities, and interest in a science-related career. The experimental students, compared with controls, had higher scores on all four measures; and even though the intervention had been aimed at encouraging girls, the experimental boys showed comparable enhanced attitudes. This intervention succeeded in demonstrating enhanced attitudes, but the authors acknowledge that there was no follow-up of its possible effect on students' subsequent course-taking or science pursuits.

The second intervention (Evans \& Whigham, 1995) was aimed at demonstrating a rolemodeling effect on student attitudes. Subjects were 964 ninth-grade science students, divided into experimental and control groups, with the experimental classes arranged as either mixed-sex or all-girl. Three women scientists presented material over 2 days on science careers and their suitability for women. As it turns out, given that the experimental design varied class makeup rather than the women scientists' presentations, this study is more a test of critical mass (i.e., having more than just a few girls in a setting) than of modeling. As in the first study described above, both experimental boys and girls showed more positive change in attitudes than controls pre- to postprogram. Contrary to the prediction that girls would profit more from all-girl classes, however, these classes seemed not to have been particularly advantageous; girls in all-girl classes did not differ from girls in mixed-sex classes. Again, this study, although effective in changing attitudes of both girls and boys, had no follow-up assessment of sustained effect over time.

An early review summarizing evidence on what factors enhance commitment to major in science and engineering found that "there is little evidence of a contribution [of] being in summer 
science camp" (U.S. Congress, 1988, p. 1010). A later review of three studies of summer programs, two with random assignment, also found no differences between those who attended the program and controls; both groups increased their interest in a science career and planned to take more science courses (Campbell, 1994).

A much more extensive review of the National Science Foundation's Young Scholars Program (Sharp, Carey, Frechtling, \& Burgdorf, 1994) similarly found no program effect: "We can find no advantage for Young Scholars Program participants over those who applied to the program but did not attend" (p. 3). This study, which followed a large cohort of students over a 5 -year period, found that $65 \%$ of the participants $(N=3398)$ and $72 \%$ of the nonparticipants $(N=6231)$ chose to major in a science, engineering, or mathematics field. It was concluded, however, that the program was especially effective for African American students but less so for female students, with $72 \%$ of African American participants but only $33 \%$ of female participants planning a career in science. Two serious limitations to this study are worth noting, however. First, the overall NSF program, as the report acknowledges, encompasses a great diversity of programs, with some more effective than others; but the analysis did not test for possible individual program differences. Second, only half the participants responded to the follow-up surveys, which calls into question the generalizability of its findings.

To summarize, we still have much to learn about how best to intervene to encourage the science participation of girls in general, let alone minority girls in particular. Investigations to date have serious limitations: (a) Many early interventions lacked any meaningful evaluation component. (b) Subsequent evaluations have typically focused on a narrow range of outcomes, e.g., on attitudes toward science but not on participants' behavior after a program. (c) Evaluations have lacked a long-term perspective, tending rather toward short-term designs that measure change immediately postprogram. (d) Little attention has been pais to evaluating potential intervention effects on girls of minority ethnicity. (e) Response rates of the few studies that employ a follow-up are low, thus limiting generalizability.

\section{Summerscience for Girls}

In the present study we sought to evaluate in depth the effects of a single well-planned program whose goal was to enhance interest and persistence in science among middle schoolaged girls from various ethnicities, specifically comparing girls from minority and nonminority groups. Would minority and nonminority girls differ in their response to the program and in longterm outcomes?

Summerscience for Girls was funded by the National Science Foundation, by a grant awarded to the Women in Science and Engineering Program at the Center for the Education of Women, University of Michigan. Participants in the program, half of whom were to be minority students, were selected from a pool of high-achieving eighth-grade girls from across the state of Michigan. All students who applied had the recommendation of their science teacher. The program was not labeled a gifted program, but as it turned out, the girls who applied were nevertheless an elite group with high grade point average and ambition (for example, at the study's end only two of the entire sample were not planning to start college in the fall after graduation from high school).

The program took place during the early summer after the girls' completion of eighth grade. It provided a 2-week science immersion on the University of Michigan campus, with activities designed to incorporate the full range of intervention components believed to enhance interest in and commitment to the study of science (U.S. Congress, 1988). These included hands-on laboratory or field experience, exposure to female role models, informational sessions on careers and requisite training, and exercises aimed at dispelling the stereotypes associated with women doing 
science. In addition, almost half the participants were of minority status, a feature meant to capitalize on the tenet that a critical mass of participants of like gender and ethnicity would support continuing interest. Two of the 8 student leaders and 1 each of the instructors and career panelists (of 10) were themselves of minority ethnicity.

Summerscience for Girls afforded us the opportunity to evaluate the impact of the program by comparing outcomes for those girls who attended with those for applicants who did not attend. The design of the study incorporated several improvements over most previous evaluation: (a) It assessed behavior along with the psychological and attitudinal factors held to be indicative of course-taking patterns and continuing interest. (b) It focused on a critical period of development, the adolescent years (8th to 12th grade), when attrition is most likely to occur. (c) The investigation was longitudinal, which allowed for a look at possible mechanisms of sustained interest and committed behavior over time. (d) The issue of minority participation was specifically addressed. (e) The design capitalized on the availability of a well-matched comparison group: the applicants who were not selected to participate in the program. These girls were followed over the same period as program participants. These two samples of girls were well-matched in that they did not differ preprogram on relevant background measures, on attitudes toward science, and their science experiences. (e) A high response rate was obtained through intensive efforts to track both participants and nonparticipants at two follow-up assessments.

Based on the high quality of program design and its attention to issues facing minority participants, the following hypotheses were proposed.

- Hypothesis 1: It was predicted that the program would have a main effect: that following the program, participants, in comparison with applicants (i.e., girls who applied but did not attend), would report more positive attitudes about science and show more behavior consistent with a continuing pursuit of science training.

- Hypothesis 2: It was expected that the program would be equally beneficial for minority and nonminority participants.

\section{Method}

\section{Sample}

Of the 321 girls who applied to Summerscience for Girls, $273(85 \%)$ returned the initial questionnaire. Forty-five girls were selected by program administrators to participate in the program, and the remaining 228 applicants served as the comparison group for this study. The program planners sought to establish a participation group that would represent a balance between urban and rural schools, schools of varying size, and schools from different geographic regions of the state. Table 1 shows the number of girls from schools of varying size and location. Half the girls were to be of minority ethnicity and some participants, both minority and nonminority, were selected because they were less likely to have been exposed to science concepts or activities outside school (mostly from rural areas or from nonscience-oriented families). This preference for participants with limited opportunities was aimed at offsetting the number of girls applying who were from schools or families that would likely provide a richer exposure to science.

Sixty-two subjects were excluded from the final sample: these included 29 girls ( 7 participants, 22 applicants) who had missing data for essential outcome variables; 30 girls whose ethnicity could not be reliably established; and 3 girls who identified themselves as Asian American (not an underrepresented minority). Only one girl refused to be interviewed when contacted in a follow-up; attrition was thus the result more of a failure to locate some girls than of their reticence to respond. 
Table 1

School size and location and subjects' ethnicity for four Ethnicity $\times$ Participation groups

\begin{tabular}{|c|c|c|c|c|}
\hline & \multicolumn{2}{|c|}{ Nonminority } & \multicolumn{2}{|c|}{ Minority } \\
\hline & Participants & Applicants & Participants & Applicants \\
\hline \multicolumn{5}{|l|}{ Size of school } \\
\hline$<300$ students & 9 & 25 & 0 & 5 \\
\hline$\geq 300$ students & 15 & 130 & 14 & 10 \\
\hline \multicolumn{5}{|l|}{ Location of school } \\
\hline Metropolitan/city & 4 & 44 & 11 & 7 \\
\hline Town/suburban & 12 & 74 & 2 & 5 \\
\hline Rural & 8 & 35 & 1 & 1 \\
\hline \multicolumn{5}{|l|}{ Ethnicity } \\
\hline African American & 0 & 0 & 11 & 10 \\
\hline Latino & 0 & 0 & 2 & 4 \\
\hline Native American & 0 & 0 & 1 & 3 \\
\hline White & $\underline{24}$ & 156 & 0 & 0 \\
\hline Total number of girls & $\overline{24}$ & $\overline{156}$ & $\overline{14}$ & $\overline{17}$ \\
\hline
\end{tabular}

Note. This information was assessed when the girls were in eighth grade, attending middle or junior high school. The number of girls for size and location of school does not always sum to the total number of girls in each group, owing to missing data.

Results were thus based on analysis of the responses of the 211 girls who had complete data on all critical variables. Girls in the final sample were designated either participants (those who attended Summerscience) or applicants (those who applied but did not attend). All were also categorized by ethnicity as either minority (self-identified as African American, Latino, or Native American) or nonminority (self-identified as White). The four groups included 14 minority participants, 24 nonminority participants, 17 minority applicants, and 156 nonminority applicants. Most of the girls in both minority groups were of African American ethnicity (Table 1).

Group comparisons showed the four groups before the program to be equivalent on a range of demographic and school-related variables. They did not differ in academic achievement as measured by seventh-grade science grades, math grades, level of mother's education, or size of school. Just one group difference, in school location, was present: minority participants and applicants were more likely than nonminority girls to be attending urban, as opposed to rural, schools.

\section{Procedure}

Data were collected from all subjects at three time points.

Time 1 (8th grade). At Time 1, through a separate mailing from the researchers and before notification of acceptance by program administrators, all applicants to Summerscience were asked to respond to a preprogram questionnaire.

Time 2 (9th grade). The Time 2 follow-up occurred 10 months postprogram, when all the girls who had returned the Time 1 questionnaire were contacted for a telephone interview.

Time 3 (12th grade). At Time 3, the entire sample was again interviewed by telephone. 
Interviewers, consisting of 12 well-trained undergraduate and graduate women, made intensive efforts to locate all subjects at Times 2 and 3.

Evaluation Questionnaire. In addition to data collection at the three time points described above, participants, but not applicants, responded to a postprogram evaluation questionnaire (designed in part by the National Science Foundation) administered the final day of attendance at Summerscience.

\section{Measures}

The study design included two independent variables-program participation (participant/ applicant) and ethnicity (minority/nonminority) — and the seven outcome variables, listed below. Outcome measures are described in more detail in the Appendix. For each measure, a high value represents a more positive orientation toward science and a science career.

Three outcome variables were measured at all three time points: (a) self-concept of science ability, (b) enjoyment and interest in science, and (c) career aspirations in science. Four outcome variables were measures only at Time 3: (a) total number of science courses taken in high school, (b) self-reported change in science interest during high school (over 3 years), (c) plans for a college major (nonscience, social science, biological or physical science), and (d) total number of science activities attended postprogram (over 3 years).

On the closing day of the program, the participants responded to a questionnaire of 16 items evaluating various aspects of Summerscience (see Appendix). It included (a) 7 items on the program's influence on attitudes and knowledge about science and science careers, (b) 6 items on degree of liking of various aspects of the program, and (c) 3 items on an overall assessment of the program.

\section{Results}

Testing the Hypotheses

Effects of Participation and Ethnicity on Outcomes Measured over Time. To determine the effects of Summerscience participation, we conducted repeated measures analyses of variance with ethnicity and participation as between-subject factors and time as a within-subject factor. We first present results of a repeated measures analysis of variance (ANOVA) procedure used to assess the attitudinal outcomes measured over time. Table 2 shows the main and interaction effects, first calculated ignoring the effect of time and then taking into account repeated measures across the three time points. Figures 1-3 illustrate these effects by showing the mean values on the outcome measures for each of the four Participation $\times$ Ethnicity subgroups.

As shown in Table 2, there was a significant main effect for ethnicity on each of the outcome variables. Examination of the mean values in Table 3 finds the sample, overall, responding at the high end of the 1-7 scale on measured outcomes. This trend notwithstanding, nonminority girls were more likely than minority girls to have higher levels of self-concept and interest in science and to have stronger science career aspirations. There was no significant main effect of program participation and no interaction effect of Participation $\times$ Ethnicity.

The within-subject component of the analysis revealed several significant findings, illustrated in Figures 1-3 that graph the mean scores over time for each of the four ethnicity by participation 
Table 2

Effect of participation and ethnicity on outcome variables measured over time

\begin{tabular}{|c|c|c|c|c|}
\hline \multirow[b]{2}{*}{ Source } & \multirow[b]{2}{*}{$d f$} & \multicolumn{3}{|c|}{$F$} \\
\hline & & Self-concept & $\begin{array}{c}\text { Enjoyment \& } \\
\text { Interest }\end{array}$ & $\begin{array}{c}\text { Career } \\
\text { Aspirations }\end{array}$ \\
\hline \multicolumn{5}{|l|}{ Effect ignoring time } \\
\hline Participation & 1207 & 1.46 & .55 & 1.33 \\
\hline Ethnicity & 1207 & $7.37 * *$ & $4.20 *$ & $4.60 *$ \\
\hline Participation $\times$ Ethnicity & 1207 & .77 & .38 & .11 \\
\hline Error & & $(1.09)$ & $(1.37)$ & $(4.08)$ \\
\hline \multicolumn{5}{|l|}{ Effect across time } \\
\hline Time & 2414 & $41.32 * * *$ & $17.61 * * *$ & $10.29 * * *$ \\
\hline Time $\times$ Participation & 2414 & 1.63 & .03 & .42 \\
\hline Time $\times$ Ethnicity & 2414 & $3.86 *$ & 2.06 & $4.36^{*}$ \\
\hline Time $\times$ Participation $\times$ Ethnicity & 2414 & $7.25 * * *$ & $4.21 *$ & $3.85^{*}$ \\
\hline Error & & $(0.32)$ & $(0.44)$ & $(1.66)$ \\
\hline
\end{tabular}

Note. This repeated measures ANOVA (Type III) tests main effects in the presence of interaction terms. $p$ values adjusted by Greenhouse-Geisser Epsilon. Values enclosed in parentheses represent mean square errors.

$* p<.05, * * p<.01, * * * p<.001$.

groups. First, an effect of time across participation and minority status reflects change on each of the three attitudinal outcome variables from preprogram through 4 years postprogram (Time 1-3). For each of the three outcome measures, change over time was negative; that is, girls in the overall sample showed a significant decline in science self-concept and expressed less interest in science and in a science career.

Second, there was no Time $\times$ Participation interaction for any of the outcome measures. Contrary to our hypothesis that attending the Summerscience program would have a positive effect on self-concept, interest and enjoyment, and career ambitions in science, none of these effects was found.

Third, a significant interaction effect of Time $\times$ Ethnicity on self-concept and career aspiration (but not enjoyment and interest) indicated that the change over time on these two measures differed for minority and nonminority girls. Change from Time 1 to Time 3 was more negative for minority than for nonminority girls, as shown in Figures 1 and 3. Both groups reported

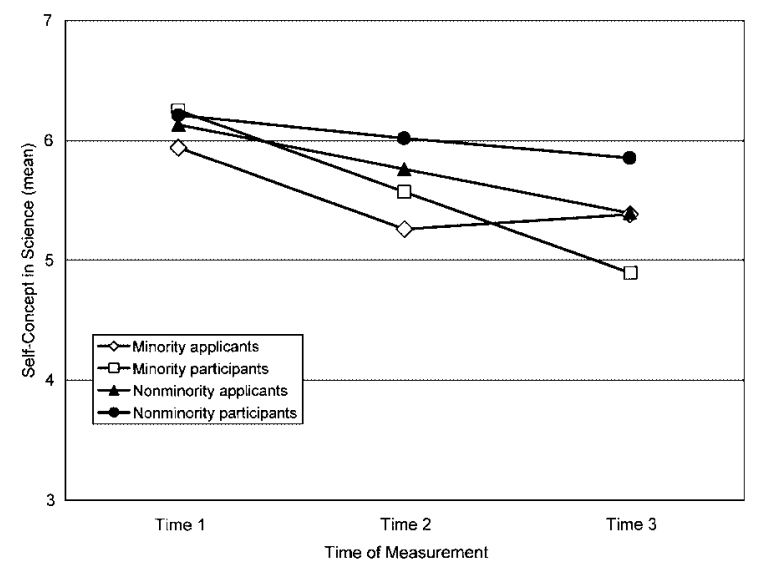

Figure 1. Self-concept in science at Times 1, 2, and 3 for four Participation $\times$ Ethnicity groups. 


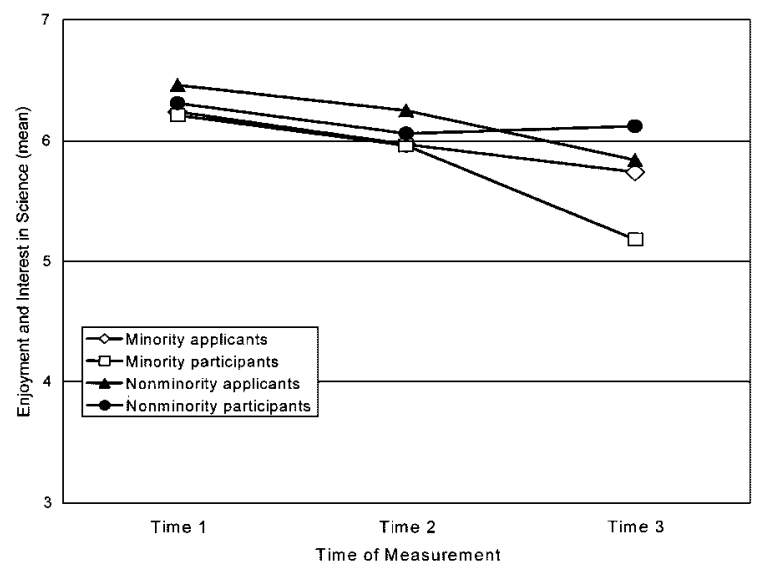

Figure 2. Enjoyment and interest in science at Times 1, 2, and 3 for four Participation $\times$ Ethnicity groups.

decreasing levels of self-concept and aspiration over time, but nonminority girls showed less decline than minority girls. Finally, a significant interaction effect of Time $\times$ Participation $\times$ Ethnicity on each of the outcome measures indicated that the four Participation $\times$ Ethnicity groups differed in degree of change over time.

The gradual divergence of the minority and nonminority groups is the more notable in that the four subgroups initially, at Time 1, held similar attitudes. Whereas some divergence in selfconcept and career ambitions in science is evident at 10 months postprogram (Time 2), differences were sizable by 4 years postprogram (Time 3 ). Here, a consistent pattern holds for participants on all three outcome measures: Nonminority participants had the highest self-concept of science, indicated the most enjoyment and interest in science, and held the strongest science career ambitions. Minority participants showed a pattern opposite that of nonminority participants. The applicants, both minority and nonminority, fell in between.

The mean values suggest where these differences lie, but we wished to test more directly the hypothesis that participants overall showed more positive outcomes over time than applicants, regardless of ethnicity. To do this we first calculated time difference scores on each of the three

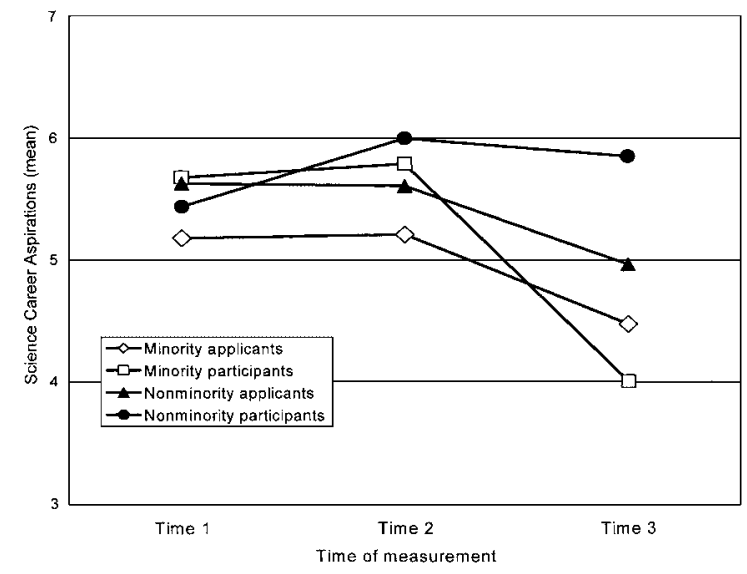

Figure 3. Science career aspirations at Times 1, 2, and 3 for four Participation $\times$ Ethnicity groups. 
Table 3

Mean and standard deviations of outcome variables measured over time for four Ethnicity $\times$ Participation groups

\begin{tabular}{llllll}
\hline & \multicolumn{2}{c}{ Nonminority } & & \multicolumn{2}{c}{ Minority } \\
\cline { 2 - 3 } \cline { 5 - 6 } & Participants & Applicants & & Participants & Applicants \\
\hline Self-concept & & & & \\
$\quad$ Time 1 & $6.2(0.5)$ & $6.1(0.7)$ & & $6.3(0.5)$ & $5.9(1.1)$ \\
Time 2 & $6.0(0.5)$ & $5.8(0.7)$ & & $5.6(0.8)$ & $5.3(0.9)$ \\
$\quad$ Time 3 & $5.9(0.5)$ & $5.4(0.9)$ & & $4.9(0.9)$ & $5.4(1.1)$ \\
Enjoyment \& interest & & & & $6.2(0.9)$ & $6.2(0.7)$ \\
$\quad$ Time 1 & $6.3(0.8)$ & $6.5(0.7)$ & & $6.0(1.2)$ & $6.0(1.2)$ \\
Time 2 & $6.1(1.0)$ & $6.3(0.8)$ & & $6.0(1.2)$ & $5.7(1.1)$ \\
Time 3 & $6.1(0.9)$ & $5.8(1.0)$ & & $5.2(1.0)$ & $5.2(1.5)$ \\
Career aspirations & & & & $5.7(1.4)$ & $5.2(1.5)$ \\
$\quad$ Time 1 & $5.4(1.5)$ & $5.6(1.3)$ & & $5.8(1.1)$ & \\
Time 2 & $6.0(1.0)$ & $5.6(1.2)$ & & $5.0(1.8)$ & \\
Time 3 & $5.9(1.7)$ & $5.0(2.1)$ & & $4.0)$ \\
\hline
\end{tabular}

attitudinal measures by subtracting Time 1 values from Time 2 values and Time 1 values from Time 3 values. These difference scores reflected change over time, with a higher score indicating more positive change. Using ANOVA, we then examined the effects of participation and ethnicity on these difference scores.

Table 4 shows the mean differences and $F$ statistics for each of the four subgroups and comparisons of participants and applicants within ethnicity. Although the scores showed a decline on most measures (negative scores) and for most groups, significant differences did emerge between the groups. Among nonminority girls, participants were significantly more likely than applicants to have higher self-concept of science ability, enjoyment and interest in science, and career aspirations in science at Time 3 than at Time 1. In addition, a marginally significant difference suggested that nonminority participants were more likely than nonminority applicants to have higher career aspirations in science at Time 2 than at Time 1.

Table 4

Mean time difference scores on outcome variables for participants versus applicants within ethnicity

\begin{tabular}{|c|c|c|c|c|c|c|}
\hline \multirow{2}{*}{$\begin{array}{l}\text { Time Difference } \\
\text { Measure }\end{array}$} & \multicolumn{3}{|c|}{ Nonminority } & \multicolumn{3}{|c|}{ Minority } \\
\hline & Participants & Applicants & $F$ & Participants & Applicants & $F$ \\
\hline \multicolumn{7}{|l|}{ Self-concept } \\
\hline Time 3-Time 1 & -0.4 & -0.7 & $6.72^{\dagger}$ & -1.4 & -0.6 & $4.33^{* *}$ \\
\hline Time 2 -Time 1 & -0.2 & -0.4 & NS & -0.7 & -0.7 & NS \\
\hline \multicolumn{7}{|c|}{ Enjoyment \& interest } \\
\hline Time 3 -Time 1 & -0.2 & -0.6 & $4.07 * *$ & -1.0 & -0.5 & NS \\
\hline Time 2 -Time 1 & -0.3 & -0.2 & NS & -0.3 & -0.3 & NS \\
\hline \multicolumn{7}{|l|}{ Career aspirations } \\
\hline Time 3 -Time 1 & 0.3 & -0.8 & $4.77 *$ & -1.7 & -0.7 & NS \\
\hline Time 2 -Time 1 & 0.5 & 0 & $3.41 *$ & -0.1 & 0 & NS \\
\hline
\end{tabular}

Note. Difference scores were calculated by subtracting the earlier time value from the later time value. Higher positive or negative numbers indicate more positive or negative attitudes to science, respectively. A mean value of 0 indicates no change over time. NS = nonsignificant $F$ statistic.

$* p<.066, * * p<.05, \uparrow p<.01$. 
For the minority girls, only the comparison between participants and applicants on selfconcept was significant, but in a direction opposite of that predicted. It was the minority participants who were significantly more likely than minority applicants to show greater decline in self-concept between Time 1 and Time 3. The other two comparisons between minority participants and applicants, on interest and enjoyment and aspirations, were not significant, but the trends from Time 1 to Time 3 were again in a direction opposite of that predicted. Thus, the results supported our hypotheses, in part: Summerscience had a positive effect for nonminority girls only, whereas it appeared to have had a negative influence among minority participants.

Effects of Participation and Ethnicity on Outcomes Measured Only at Time 3. Table 5 presents the results of an ANOVA assessing the effects of Summerscience participation and ethnicity on the four outcome measures at Time 3 only. Ethnicity showed a significant effect on the number of high school science courses taken and the change in science interest over time. Individual contrast tests indicated that nonminority girls, compared with minority girls, took significantly more high school science courses (means of 3.61 vs. 3.03, respectively) and also had more positive self-reported change in science interest (means of 5.05 vs. 4.26 , respectively). This finding is consistent with the longitudinally measured differences in outcome between minority and nonminority girls reported above. Minority and nonminority groups did not differ, however, in the number of science activities pursued during the high school years or in plans to major in science in college.

Finally, Table 5 shows a significant interaction effect of Participation $\times$ Ethnicity on 3 of the 4 outcome measures: number of high school science courses, plans for college major, and change in science interest. Table 6 compares participants and applicants within ethnicity on these measures. A pattern emerges that in many respects parallels that shown at Time 3 in Table 3: Minority participants, compared with minority applicants, were significantly less likely to report that they planned to major in science and that their science interest increased over time. Minority participants and applicants did not differ in the number of high school science courses taken.

Among nonminority girls, participants and applicants did not differ in plans to major in science or in self-reported changes in science interest over time. However, although marginally significant, participants had taken more high school science courses than applicants.

Summary. These results partly confirm just one of the two hypotheses proposed. We had predicted that participation in Summerscience would have a positive effect on girls' attitudes toward science and plans for their science education and careers. No such main effect was found.

Table 5

Effect of participation and ethnicity on outcome variables measured only at Time 3

\begin{tabular}{lcccc}
\hline & \multicolumn{3}{c}{$F$} \\
\cline { 2 - 5 } Effect & $\begin{array}{c}\text { No. of HS } \\
\text { Science }\end{array}$ & $\begin{array}{c}\text { Plan College } \\
\text { Science } \\
\text { Courses }\end{array}$ & $\begin{array}{c}\text { Self-reported } \\
\text { Change in } \\
\text { Science Interest }\end{array}$ & $\begin{array}{c}\text { No. of Science } \\
\text { Activities } \\
\text { Postprogram }\end{array}$ \\
\hline Participation & 0.00 & 1.74 & 2.66 & 0.19 \\
Ethnicity & $8.10^{* *}$ & 1.80 & $6.94 * *$ & 0.46 \\
Participation $\times$ Ethnicity & $3.94^{*}$ & $4.44^{*}$ & $4.10^{*}$ & 2.16 \\
\hline
\end{tabular}

Note. Degrees of freedom for all $F \mathrm{~s}=1207$.

$* p<.05, * * p<.01$. 
Table 6

Mean scores for participants versus applicants within ethnicity on outcomes measured only at Time 3

\begin{tabular}{|c|c|c|c|c|c|c|}
\hline & \multicolumn{3}{|c|}{ Nonminority } & \multicolumn{3}{|c|}{ Minority } \\
\hline & Participants & Applicants & $F$ & Participants & Applicants & $F$ \\
\hline No. of HS science courses & $4.1(1.1)$ & $3.5(1.4)$ & $3.43^{*}$ & $2.7(1.0)$ & $3.3(1.8)$ & 1.43 \\
\hline Plan college science major & $3.1(1.4)$ & $2.9(1.5)$ & 0.57 & $2.1(1.5)$ & $3.1(1.4)$ & $4.02^{\dagger}$ \\
\hline $\begin{array}{l}\text { Self-reported change in } \\
\text { science interest }\end{array}$ & $5.2(1.6)$ & $5.0(1.6)$ & 0.14 & $3.6(2.1)$ & $4.8(1.7)$ & $4.58^{\dagger}$ \\
\hline
\end{tabular}

Note. Standard deviation enclosed in parentheses.

$* p<.066, \uparrow p<.05$.

Rather, the effect held for nonminority girls only. Results indicated unequivocally that the program effect was more positive for nonminority girls than for minority girls.

The second hypothesis, that the program would be equally salutary for minority and nonminority girls, was not supported. The program was more beneficial for nonminority girls.

\section{Post Hoc Analyses: Exploring the Differential Effects of Summerscience}

Accounting for Differences in Disadvantage. Results of this study suggest that Summerscience enhanced the confidence and aspirations of nonminority participants, whereas its effect for minority participants was inhibiting, if not discouraging. Given the troubling implications of these findings, we undertook further analyses to explore possible explanations for this outcome. We first speculated that differences might have arisen not from different reactions to the program but from differences in some background factor unrelated to the program. For instance, if nonminority girls, in general, were more advantaged and thus had greater access to resources that support interest and motivation in science, the results might be explained by degrees of difference in advantage. It is the case that program selection sought to favor some girls with limited opportunities for science enrichment; it seemed possible, though, that minority and nonminority participants might still differ in level of advantage.

To test for this, an advantage scale (see Appendix) was constructed post hoc to include parental educational level, parental occupation level, family configuration (single- or two-parent), and request for financial aid (to the program). A higher score indicated greater advantage. We first examined the effects of participation and ethnicity on this measure. Results from an ANOVA showed, as speculated, a significant main effect of ethnicity, $F=16.635, p<.001$, with minority girls overall, $M=1.65$, less advantaged than nonminority girls, $M=2.74$. However, we found no effect of participation, nor of an interaction of participation with ethnicity; that is, participants and applicants, assessed within either minority or nonminority status, did not differ in level of advantage.

As a more stringent test, we repeated the ANOVA analyses on all 7 outcome measures described above, but with the advantage scale included as a covariate. These ANCOVA $F$ statistics were compared with those presented in Table 2 and Table 5. If advantage were to account for group differences, one would expect the significant $F$ s found in the initial ANOVAS to disappear with the covariate included.

The results of these analyses showed a single instance where the addition of the covariate decreased a previously significant $F$ to nonsignificance. This occurred for the effect of time and ethnicity on career aspirations (compare ANCOVA $F=2.82, p<.08$, with ANOVA $F=4.36$, 
$p<.05$, in Table 2). This finding suggests that nonminority girls' relatively stronger science career aspirations over time, compared with minority girls, may have been related in part to their greater advantage. More important, however, degree of advantage did not explain the overall finding of group differences favoring nonminority participants.

Participants' Evaluations of the Program. We next speculated that some aspect of the Summerscience program itself might have led to the different responses of minority and nonminority participants, that somehow the program experience was positive for nonminority girls but negative for minority girls. To test for this possibility, we first examined the participants' evaluation of Summerscience, which was assessed by questionnaire on the final day of the program. The girls were asked about specific aspects of the program and about their overall experience.

Results of $t$ tests showed that only 3 of the 16 questions differentiated nonminority and minority participants; each of these questions dealt with the program generally, not with any specific aspect. Nonminority girls were significantly more likely than minority girls to (a) say they would recommend programs like Summerscience to friends who were interested in science and math (nonminority $M=3.7$, minority $M=3.3, t=2.6, d f=35, p<.01$ ); (b) give a positive overall assessment of the program (nonminority $M=6.5$, minority $M=5.6, t=2.0, d f=15.4, p<.05$ ); and (c) say they would like to participate in a similar project if given the opportunity (nonminority $M=3.8$, minority $M=3.5, t=1.7, d f=23.3, p<.05$ ) (all one-tailed tests of significance). The groups did not differ in their view of any of the specific components of the program.

In addition to contrasting the two groups' response to the program, we also examined the correlations among the same three program assessment questions that differentiated minority and nonminority participants and the seven outcome variables measured at Time 3 . These results, shown in Table 7, lend some support to the conclusion that participants' overall experience in Summerscience accounted in part for later differences in attitudes and behavior. Participants' overall positive/negative assessment of the program was significantly related to six of the Time 3 outcome measures. Although the relationship between the question about recommending to friends and outcomes was not as consistently significant, each one was in a positive - that is, expected-direction. The number of cases was too small to allow an adequate test of these relationships within ethnicity, but correlations generated separately for minority and nonminority girls were consistent with those shown in Table 7.

Table 7

Correlations between program evaluation questions and Time 3 outcome measures for all participants

\begin{tabular}{|c|c|c|c|c|c|c|c|}
\hline \multirow[b]{2}{*}{ Evaluation Questions } & \multicolumn{7}{|c|}{ Outcome Measures } \\
\hline & $\begin{array}{c}\text { Self- } \\
\text { Concept }\end{array}$ & $\begin{array}{l}\text { Enjoy \& } \\
\text { Interest }\end{array}$ & $\begin{array}{c}\text { Career } \\
\text { Ambitions }\end{array}$ & $\begin{array}{l}\text { No. of } \\
\text { HS } \\
\text { Science } \\
\text { Classes }\end{array}$ & $\begin{array}{c}\text { Self-reported } \\
\text { Change in } \\
\text { Science Interest }\end{array}$ & $\begin{array}{l}\text { College } \\
\text { Science } \\
\text { Major }\end{array}$ & $\begin{array}{c}\text { No. of } \\
\text { Science } \\
\text { Activities } \\
\text { Postprogram }\end{array}$ \\
\hline $\begin{array}{l}\text { Overall assessment } \\
\text { of Summerscience }\end{array}$ & $0.41 * *$ & $0.52 * * *$ & $0.44 * *$ & $0.34 *$ & $0.36^{*}$ & $0.38 * *$ & 0.17 \\
\hline $\begin{array}{l}\text { Recommend } \\
\text { program to friend }\end{array}$ & $0.29 *$ & $0.31 *$ & 0.25 & 0.25 & 0.26 & 0.15 & 0.27 \\
\hline $\begin{array}{l}\text { Desire to participate } \\
\text { in similar project }\end{array}$ & 0.24 & $0.33 *$ & 0.19 & 0.04 & 0.24 & 0.25 & 0.13 \\
\hline
\end{tabular}

Note. Probability levels indicate one-tailed tests of significance.

$* p<.05, * * p<.01, * * * p<.001$. 
Results of the $t$ tests and correlations suggest that the participants' general feelings about Summerscience, but not their evaluation of specific program components, may explain in part minority and nonminority differences in outcome.

\section{Discussion}

That this study failed to show a main effect of the Summerscience program contradicted our hypothesis; on reflection, however, this may not come as a surprise. Although one might have wished for more, the apparent lack of effect parallels other results reported earlier (Matyas \& Malcom, 1991; Sharp et al., 1994; U.S. Congress, 1988). What was unexpected, however, was that nonminority and minority program participants had different outcomes that have implications for their ongoing science course-taking and learning. Whereas nonminority participants maintained relatively high levels of self-concept of science ability, interest and enjoyment, and aspirations to pursue science, minority participants saw their self-concept and attitudes diminish over time to levels lower than all other groups, whether participant or applicant. This is the more surprising because some studies have found that minority students tend to report equivalent or higher levels of self-concept and aspirations than majority students [Graham (1994), Solorzano (1992); see also Allen \& Boykin (1992), Bowman \& Howard (1985), and Wilson (1998), for general discussions of cultural influences on the achievement motivation of African American students]. Thus, the present study seems to raise more questions than it provides answers. We explore in the following, however, some possible explanations for the results and recommendations for further study.

First, one could propose the obvious - that the minority girls in Summerscience simply manifested the decreasing academic motivation that typifies girls of this age group in general (Eccles, 1997; U.S. Department of Education, 1998); if this were the explanation, however, why did minority applicants not show a similar degree of decline? Second, perhaps minority participants experienced a kind of loss of self-confidence that characterizes some participants in gifted programs whereby the stiffer competition of gifted peers causes them to down-rate their own abilities, in this case, science self-concept (Hoge \& Renzulli, 1993; Marsh, Chessor, Craven, $\&$ Roche, 1995). If this were the explanation, however, why were nonminority participants not similarly debilitated? Why did they maintain higher levels of self-concept and attitudes than all groups?

Neither scenario explains the different reactions of minority and nonminority participants compared with the minority and nonminority applicants. More plausible are explanations that point (a) to some difference between groups resulting from selection bias; (b) to some aspect of the program content itself; (c) to an unanticipated effect of racial bias either as it affected selection or was present in the program's setting; or (d) to an interaction over time with postprogram experience-in school, family, or community. Although the data are inconclusive, they give some hints of what may be at issue.

\section{Possible Selection Bias}

It is possible that group differences may have arisen out of selection bias, but the data do not support this conclusion. When assessed preprogram, the groups were comparable on 4 of the 5 relevant background variables, i.e., on science and math grades, level of mother's education, and school size. It is the case that minority girls overall were more likely than nonminority girls to come from urban schools, but this held for both participants and applicants and thus would not explain either the ensuing differences between these two groups. 
The four groups also did not differ in the initial preprogram assessments of attitudes about science and science experience. These include self-concept of science ability, interest and enjoyment of science, and intent to pursue a science major, as well as the number of informal and formal science activities outside school. Thus, we cannot conclude that the groups differed at the outset in substantive ways that brought about the observed divergences over time.

\section{Dose of Reality}

The data suggest that some aspect of the program itself may have contributed to the results. The minority participants differed from nonminority participants not in their appraisal of the individual components, but in their overall evaluation of the program: in their reticence to participate in other similar programs and in their attesting that they would not recommend the program to friends. It is possible that the program may have served as a dose of reality for some of the participants, with a more poignant effect for minority girls.

The program components, which exposed participants to typical laboratory settings and to practicing women scientists, were aimed at giving the girls a clear and positive view of what becoming a scientist entails. Perhaps the prospects appeared more daunting to minority participants, such that the initial enthusiasm generated by program attendance eroded over time, especially during the high school years. This suggests some interaction of the intervention with later experience.

A second aspect of the reality check could be relevant. The program may have made more salient the barriers and double cost that minority girls, as female and minority, face in seeking science training and a science career. Such nontraditional pursuits may conflict with what the larger culture and peers expect and thereby contradict a self-identity attached to science pursuits. The social context should not be underestimated (Eccles-Parsons et al., 1983; Urdan \& Maehr, 1995). The high-achieving girl may find herself at odds with her desire for social approval and solidarity with a peer culture that tends to devalue school and academic achievement. This may indeed be a factor for most adolescents, but it may be particularly salient for minority girls (Ford \& Harris, 1996).

The process of choosing a career may be complex for minority girls. We know that for girls in general, compared with boys, this process does not follow a one-to-one correspondence with either talent or interest (Farmer, 1997; Lips, 1992; Schulenberg, Goldstein, \& Vondracek, 1991). Grades in science, for example, predict to the choice of college science major for boys, but not for girls (Maple \& Stage, 1991; National Center for Educational Statistics, 1990). Girls with strong commitment to career and strong background in science more frequently switch out of science to other fields, where they may have more interest or sense of comfort (Farmer et al., 1995). It is possible that this trend is exaggerated for minority girls, that becoming a scientist presents a double dissonance some do not want to endure (Cohn, 1997; Malcom, Hall, \& Brown, 1976).

\section{Preferential Selection and Discrimination}

Summerscience had as a goal that approximately half the participants would be of minority status; the program thus represented an instance of affirmative action-a remedy for discrimination currently much under fire (Greenhouse, 1997; Kunen, 1996; Tierney, 1997). What was the effect of this feature of the program? Almost three-quarters of the minority participants and over half of the minority applicants attended inner-city schools that are predominantly minority. Summerscience may well have been the participants' first experience with either preferential selection or a predominantly majority setting. Either the method of selection or the setting of the 
program could have posed a "stereotype threat," as described by Steele and Aronson (1995), whereby minority students, in the face of being judged, come to disidentify with the area of threat-in this case the science domain. Research has shown that students may have difficulty interpreting the meaning of preferential selection. Some work would predict that the minority participants in Summerscience would be protected by knowing they had been selected on the basis of merit (Schneider, 1994). Other investigations suggest the opposite, however, that the vanguard who are identified with a domain are the most vulnerable (Steele, 1997).

Exposure to ongoing student life on the University of Michigan campus may also have dampened minority participants' enthusiasm. The university is committed to fostering a diverse student body; indeed, $25 \%$ of undergraduates are of minority ethnicity. Within this diversity, however, some students choose to self-segregate by ethnicity in their living arrangements and student organizations (Holmes, 1999). Research on desegregation suggests that such environments may be less beneficial than those that are more thoroughly integrated (Schofield, 1997; Wells \& Crain, 1994). Perhaps Summerscience minority participants hesitated at the prospects of pursuing a rigorous curriculum in such a setting.

Finally, although the program structure established, as planned, a critical mass of minority participants, this may not have provided the best setting for introducing students to a predominantly majority university. Although the program provided minority counselors and science role models, it was not structured expressly to integrate the participants. The extent to which the minority participants themselves cohered as a group may have inhibited their access to the larger community and thereby contributed to disidentification with the program's goals (Schofield, 1997; Steele, 1997).

\section{Postprogram Support}

The present study had an important advantage in its longitudinal design: The flagging selfconcept and attitudes of the minority participants were not pronounced at Time 2, 1 year postprogram. Rather, the decrease occurred over time, over 3 years, suggesting an interaction of the program experience and later circumstance. We speculate that the environment to which students returned postprogram may have contributed to the minority participants' loss of commitment to science over time. Having been sensitized by the program experience, they, more than the minority applicants, may have felt more keenly a lack of support or implied skepticism of peers, teachers, or family (American Association of University Women, 1991, 1992; Steele, 1997). The minority participants may have also been better equipped to weigh realistically the costs and values of pursuing science as opposed to other fields (Eccles-Parsons et al., 1983; Riesz, McNabb, Stephen, \& Ziomek, 1994; Urdan \& Maehr, 1995). Without ongoing support expressly aimed at their science interests, perhaps they came to see themselves as better suited in the long run to other endeavors.

\section{Limitations of the Study and Future Research}

Given the exploratory nature of the present study, it would be important in future research to consider the possible limitations of the current design: namely, the small sample size, possible selection bias, and generalizability. The relatively small number of students participating in the Summerscience program is a concern. We hold, however, that the study nevertheless warrants attention. Findings such as these, that are based on a small number of cases but are highly significant, indicate a strong effect size. Such results suggest that a larger sample could yield similar, if not stronger, effects. Moreover, the consistency of the present results, for example, that 6 of 7 interaction effects were significant (shown in Tables 2 and 5), attests to the strength of the findings. 
It is possible that something about the original selection process contributed to group differences over time, but this does not seem to be the case. We, as the researchers, did not take part in the process, nor were we privy to exactly how the program administrators arrived at the final group of participants. The program planners indicated, however, that they were seeking to balance the representation of school size and geographic location and that they included, by design, at least some girls who might otherwise have limited access to science enrichment. The girls who were selected for the program represented the broad population of middle school girls who excel in science in the state of Michigan. They were drawn from the entire state and from a large variety of school districts and middle schools. Moreover, the same selection procedures were used for both minority and nonminority girls so that any sample bias resulting from the way participants were chosen would have been the same for both groups.

Finally, on the question of generalizability, we acknowledge that evaluation research rarely uses random selection of subjects and commonly relies, as did we, on naturally occurring samples, which are often small. In the present case, however, we find no clear basis to question the generalizability of the results; that is, we would have no special reason to expect a different result, given a comparable study of a similar intervention. Viewed as a formative evaluation, it is hoped that the present study can be useful to those planning future research. Further work is needed to replicate the present findings with other samples and in other contexts.

\section{Conclusion}

Despite the unanticipated consequences of Summerscience, we are not ready to suggest that interventionists should abandon such programs. The nonminority participants in this study clearly showed positive effects, above all groups. The program also may have had other salutary effects of which we are unaware. Some of the minority girls, for instance, went on in science. We have to ask what effect such a program might have on the persistence of these few. Might it inspire the special determination needed to pursue their science interests? We also ask how Summerscience affected the science literacy of all participants, even those who switched to other fields. They did finish high school still in the pipeline-that is, with enough science courses to go on in science if they so chose. Did Summerscience help put them in a better position to profit from their ongoing studies, of whatever sort?

We conclude that the effects of interventions such as Summerscience are complicated and emphasize that formative evaluation such as the present study can call attention to potential problems in program design and point the way to better interventions. Present results serve to alert both program designers and evaluators to (a) the possibility of unintended interactions between well-meaning interventions and the ethnicity of participants and (b) the importance of investigating program effects over time. Even though our evaluation was not able to disentangle the interaction between program, postprogram completely, and minority status, it does suggest the importance of taking into account such interactions in future program design and evaluation. Most significant, the present study cautions against simplistic interventions and demonstrates the value of in-depth, longitudinal evaluation in identifying both the virtues and pitfalls of such science programs. We hope this work can help program planners develop interventions that are more effective in encouraging both minority and nonminority girls to enter science fields.

The research reported in this article was funded by a grant from the Office of Vice President for Research at the University of Michigan. The authors thank Ken Guire for statistical advice, Cinda-Sue Davis and the Women in Science and Engineering Program at the University of Michigan for allowing access to their program, the students who assisted in the collection of data, and especially the girls who participated in this study. 
Appendix

Measures were coded so that a high value indicates a more positive orientation toward science or a career in science.

Outcome measures

Self-concept in Science (measured at Time 1, 2, and 3)

"How good are you at science?"

"How good are you at science compared with most other students in your science classes?"

$(1=$ not too good; $7=$ extremely good $)$

Enjoyment and Interest in Science (measured at Time 1,

2 and 3)

"How much do you enjoy science?"

"How interesting is science to you?"

$(1=\mathrm{a}$ great deal/extremely interesting; $7=$ not too much/ interesting)

Career Aspirations in Science (measured at Time 1, 2, and 3) Cronbach Alpha Time 1 Time 2 Time 3

$\begin{array}{lll}.65 & .64 \quad .75\end{array}$

"How interested are you in a career in science?"

"How likely is it that you will actually have a career in science?"

$(1=$ not very interested/not at all likely; $7=$ very interested/very likely)

Science Courses in High School (measured only at Time 3)

Total number of terms of science taken in high school

Self-reported Change in Science Interest (measured only at Time 3)

"In general, over the past 3 years, have you become more or less interested in science?" $(1=$ much less; $7=$ much more $)$

Plans for College Science Major (measured only at Time 3)

"What do you think you might major in?"

( $1=$ nonscience [e.g., art, philosophy, foreign language]; $2=$ social science [e.g., psychology, economics]; 3 = biological/physical science [e.g., biology, chemistry, engineering])

Number of Science Activities Postprogram (measured only at Time 3)

Total number of formal and informal science-related activities in the past 3 years (e.g., science clubs, science camps, science reading, science projects).

Program Evaluation Questions (assessed the final day of the Summerscience Program)

Overall Assessment of Program

How would you rate Summerscience overall? $(1=\mathrm{I}$ didn't like it at all; $7=\mathrm{I}$ loved it $)$

I will recommend projects like this to friends who are interested in science and mathematics. $(1=$ strongly disagree; $4=$ strongly agree $)$

If I had the opportunity, I would participate in a similar project. $(1=$ strongly disagree; $4=$ strongly agree)

Program Influence

Participation in this project has increased my interest in science $(1=$ strongly disagree; $4=$ strongly agree)

Participation in this project has increased my understanding of the research process $(1=$ strongly disagree; $4=$ strongly agree $)$

How much has Summerscience increased your liking of science? $(1=$ not at all; $7=\mathrm{a}$ great deal)

How much have you learned from Summerscience about what a scientist does? $(1=$ some; 
$7=$ enormous amount)

How much have you learned from Summerscience about the education necessary to become a scientist? $(1=$ some; $7=$ enormous amount $)$

How much has Summerscience increased your awareness of the role of women in science? $(1=$ not very much; $7=$ a great deal $)$

How has Summerscience affected your plans for a career in science? $(1=$ less committed to science career; $7=$ more committed to science career)

Assessment of Program Components

How would you rate: 1) your focus project, 2) the computer project, 3) the career panels,

4) the ethics component, 5) the tours and the demonstrations, 6) living in the dorm?

$(1=\mathrm{I}$ didn't like it at all; $7=\mathrm{I}$ loved it $)$

Advantage Scale (assessed at Time 1)

Each of the four items listed below was first scored according to high or low advantage. The scores were then summed, resulting in a scale ranging from 1 to 4 , with a score of 4 indicating the highest level of advantage.

(1) Whether or not financial aid was requested; (2) occupational level of parents (scored high if either parent employed in white collar or professional occupation); (3) educational level of parents (scored high if either parent had a college degree); (4) whether girl lived with both parents or lived with a single parent or other adult.

\section{References}

Allen, B.A. \& Boykin, A.W. (1992). African-American children and the educational process: Alleviating cultural discontinuity through prescriptive pedagogy. School Psychology Review, 21, 586-596.

American Association of University Women. (1991). Shortchanging girls, shortchanging America: A nationwide poll to assess self-esteem, educational experience, interest in math and career aspirations of girls and boys ages 9-15. Washington, DC: Author.

American Association of University Women. (1992). How schools shortchange girls. The AAUW report: A study of major findings on girls and education. New York: Marlowe.

Anderman, E.M. \& Maehr, M.L. (1994). Motivation and schooling in the middle grades. Review of Educational Research, 64, 287-309.

Astin, A.W. \& Astin, H.S. (1992). Undergraduate science education: The impact of different college environments on the educational pipeline in the sciences. Los Angeles: UCLA Higher Education Research Institute.

Bowman, P.J. \& Howard, C. (1985). Race-related socialization, motivation, and academic achievement: A study of black youths in three-generation families. Journal of the American Academy of Child Psychiatry, 24, 134-141.

Campbell, P.B. (1994, April). Gender equity in mathematics: Moving forward, backward, or going nowhere fast. Paper presented at the annual meeting of the American Educational Research Association, New Orleans.

Chronicle of Higher Education (1997, August 29). Almanac Issue.

Chu Clewell, B. \& Ginorio, A.B. (1996). Examining women's progress in the sciences from the perspective of diversity. In Davis, C.S., Ginorio, A.B., Hollenshead, C.S., Lazarus, B.B., \& Rayman, P.N. (Eds.), The equity equation (pp. 163-231). San Francisco: Jossey-Bass.

Clewell, B.C., Anderson, B.T., \& Thorpe, M. (1992). Breaking the barriers: Helping female and minority students succeed in mathematics and science. San Francisco: Jossey-Bass. 
Clewell, B.C., Thorpe, M.E., \& Anderson, B.T. (1987). Intervention programs in mathematics, science, and computer science for minority and female students in grades four through eight. Princeton, NJ: Educational Testing Service.

Cohn, J. (1997). The effects of racial and ethnic discrimination on the career development of minority persons. In Farmer, H.S. \& Associates (Eds.), Diversity and women's career development (pp. 161-171). Thousand Oaks, CA: Sage.

Davis, B.G. \& Humphreys, S. (1985). Evaluating intervention programs: Applications from women's programs in math and science. New York: Teachers College Press.

Davis, C.-S. \& Rosser, S.V. (1996). Program and curricular interventions. In Davis, C.S., Ginorio, A.B., Hollenshead, C.S., Lazarus, B.B., \& Rayman, P.N. (Eds.), The equity equation (pp. 232-264). San Francisco: Jossey-Bass.

Eccles, J. (1997). User-friendly science and mathematics: Can it interest girls and minorities in breaking through the middle school wall? In Johnson, D. (Ed.), Minorities and girls in school: Effects on achievement and performance (pp. 65-104). Thousand Oaks, CA: Sage.

Eccles-Parsons, J.S., Adler, T.F., Futterman, R., Goff, S.B., Kaczala, C.M., Meece, J.L., \& Midgley, C. (1983). Expectancies, values, and academic behaviors. In Spence, J.T. (Ed.), Achievement and achievement motivation (pp. 75-146). New York: Freeman.

Evans, M.A. \& Whigham, M. (1995). The effect of a role model project upon the attitudes of ninth-grade science students. Journal of Research in Science Teaching, 32, 195-204.

Farmer, H.S. (1997). Theoretical overview: The longitudinal study. In Farmer, H.S. \& Associates (Eds.), Diversity and women's career development (pp. 3-33). Thousand Oaks, CA: Sage.

Farmer, H., Wardrop, J.L., Anderson, M.Z., \& Risinger, R. (1995). Women's career choices: Focus on science, math, and technology careers. Journal of Counseling Psychology, 42, 155170.

Ford, D.Y. \& Harris, J.J. III (1996). Perception and attitudes of black students toward school, achievement, and other educational variables. Child Development, 67, 11411152.

Fox, L.H. (1976). Women and the career relevance of mathematics and science. School Science and Mathematics, 26, 347-353.

Garcia Coll, C., Lamberty, G., Jenkins, R., McAdoo, H.P., Crnic, K., Wasik, B.H., \& Vazquez Garcia, H. (1996). An integrative model for the study of developmental competencies in minority children. Child Development, 67, 1891-1914.

Graham, S. (1994). Motivation in African Americans. Review of Educational Research, 64, $55-117$.

Greenhouse, L. (1997, September 22). Settlement ends high court case on preferences. New York Times, p. A1, A14.

Hoge, R.D. \& Renzulli, J.S. (1993). Exploring the link between giftedness and self-concept. Review of Educational Research, 63, 449-465.

Holmes, N.C. (1991, December). The road less traveled by girls: Educators seek ways to boost female achievement in math and science. The School Administrator, pp. 8-19.

Holmes, S.A. (1999, May 11). A most diverse university's new legal tack. New York Times, pp. A1, A20.

Hossler, D. \& Stage, F.K. (1992). Family and high school experience influences on the postsecondary educational plans of ninth-grade students. American Educational Research Journal, 29, 425-451.

Kahle, J.B. (1983). The disadvantaged majority: Science education for women (AETS Outstanding Paper for 1983). Burlington, NC: Carolina Biological Supply. 
Kahle, J.B. (1996). Opportunities and obstacles: Science education in the schools. In Davis, C.S., Ginorio, A.B., Hollenshead, C.S., Lazarus, B.B., \& Rayman, P.N. (Eds.), The equity equation (pp. 57-95). San Francisco: Jossey-Bass.

Kunen, J.S. (1996, April 29). The end of integration: A four-decade effort is being abandoned, as exhausted courts and frustrated blacks dust off the concept of "separate but equal." Time, pp. 39-45.

Lips, H.M. (1992). Gender- and science-related attitudes as predictors of college students' academic choices. Journal of Vocational Behavior, 40, 62-81.

Malcom, S.M., Hall, P.Q., \& Brown, J.W. (1976, April). The double bind: The price of being a minority woman in science (Report No. 76-R-3). Washington, DC: American Association for the Advancement of Science.

Maple, S.A. \& Stage, F.K. (1991). Influences on the choice of math/science major by gender and ethnicity. American Educational Research Journal, 28, 37-60.

Marsh, H.W., Chessor, D., Craven, R., \& Roche, L. (1995). The effects of gifted and talented programs on academic self-concept: The big fish strikes again. American Educational Research Journal, 32, 285-319.

Mason, C.L. \& Kahle, J.B. (1988). Students' attitudes toward science and science-related careers: A program designed to promote a stimulating gender-free learning environment. Journal of Research in Science Teaching, 26, 25-39.

Matyas, M.L. \& Malcom, S.M. (Eds.). (1991). Investing in human potential: Science and engineering at the crossroads. Washington, DC: American Association for the Advancement of Science.

Mullis, I. \& Jenkins, L.B. (Eds). (1988). Science learning matters: An overview of the science report card. Princeton, NJ: Educational Testing Service.

National Center for Educational Statistics. (1990). Who majors in science? College graduates in science, English, and mathematics for the high school class of 1980 (NCES 90-658). Washington, DC: U.S. Department of Education Office of Educational Research.

National Science Board. (1998). Science and engineering indicators 1998 (NSB 98-1). Arlington, VA: National Science Foundation.

National Science Foundation. (1994). Women, minorities, and persons with disabilities in science and engineering (NSF 94-333). Arlington, VA: National Science Foundation.

Riesz, E.D., McNabb, T.F., Stephen, S.L., \& Ziomek, R.L. (1994). Gender differences in high school students' attitudes toward science: Research and intervention. Journal of Women and Minorities in Science and Engineering, 1, 273-289.

Robertson, H.J. (1992). The better idea book: A resource book on gender, culture, science and schools. Ottawa, Ontario: Canadian Teachers' Federation.

Schneider, M.E. (1994, June-July). Affirmative action: The positive and negative consequences of race-based preferential selection. Poster presented at the annual meeting of the American Psychological Society, Washington, DC.

Schofield, J.W. (1997). School desegregation 40 years after Brown v. Board of Education: Looking forward and looking backward. In Johnson, D. (Ed.), Minorities and girls in school: Effects on achievement and performance (pp. 1-36). Thousand Oaks, CA: Sage.

Schulenberg, J., Goldstein, A.E., \& Vondracek, F.W. (1991). Gender differences in adolescents' career interests: Beyond main effects. Journal of Research on Adolescence, 1, $37-61$.

Science Education and Equity. Equity Coalition for Race, Gender, and National Origin. (1993, Fall-1994, Spring). University of Michigan School of Education, Programs for Educational Opportunity. vol. III, no. 2, Ann Arbor, Michigan. 
Sharp, L., Carey, N., Frechtling, J.A., \& Burgdorf, K. (1994, October). Short-term impact study of the National Science Foundation's Young Scholars Program. Washington, DC: National Science Foundation, Division of Research, Evaluation, and Dissemination.

Solorzano, D.G. (1992). An exploratory analysis of the effects of race, class, and gender on student and parent mobility aspirations. Journal of Negro Education, 61, 30-44.

Steele, C.M. (1997). A threat in the air: How stereotypes shape intellectual identity and performance. American Psychologist, 52, 613-629.

Steele, C. \& Aronson, J. (1995). Stereotype threat and the intellectual test performance of African Americans. Journal of Personality and Social Psychology, 69, 797-811.

Tierney, W.G. (1997). The parameters of affirmative action: Equity and excellence in the academy. Review of Educational Research, 67, 165-196.

Urdan, T.C. \& Maehr, M.L. (1995). Beyond a two-goal theory of motivational achievement: A case for social goals. Review of Educational Research, 65, 213-243.

U.S. Congress, Office of Technology Assessment. (1988). Educating scientists and engineers: Grade school to grad school (OTA-SET-377). Washington, DC: U.S. Government Printing Office.

U.S. Department of Education. (1998, April). Mathematics and science study points out problems and positive solutions. Community Update, no. 56, p. 5. Washington, DC: Author.

Wells, A.S. \& Crain, R.L. (1994). Perpetuation theory and the long-term effects of school desegregation. Review of Educational Research, 64, 531-555.

Widnall, S.E. (1988). AAAS Presidential Lecture: Voices from the pipeline. Science, 241, 1740-1745.

Wilson, W.J. (1998). The role of the environment in the black-white test score gap. In Jencks, C. \& Phillips, M. (Eds.), The Black-White test score gap (pp. 501-510). Washington, DC: Brookings Institution Press. 